Published in final edited form as:

J Cancer Surviv. 2017 October ; 11(5): 542-552. doi:10.1007/s11764-017-0623-2.

\title{
A Systematic Review of Patient Perspectives on Surveillance after Colorectal Cancer Treatment
}

\author{
Julia R. Berian, MD, MS ${ }^{1,2}$, Amanda Cuddy, $\mathrm{MPH}^{4}$, Amanda B. Francescatti, $\mathbf{M S}^{1}$, Linda \\ O'Dwyer, MA, MSLIS ${ }^{3}$, Y. Nancy You, MD, MHSc ${ }^{4}$, Robert J. Volk, PhD ${ }^{5}$, and George J. \\ Chang, MD, MS ${ }^{4,5}$ \\ ${ }^{1}$ American College of Surgeons, Division of Research and Optimal Patient Care, 633 N. St Clair \\ St., $22^{\text {nd }}$ Floor, Chicago IL 60611 \\ ${ }^{2}$ University of Chicago Medical Center, Department of Surgery, 5841 S. Maryland Ave, Chicago IL \\ 60637 \\ ${ }^{3}$ Northwestern University, Galter Health Sciences Library, 303 E. Chicago Avenue, Chicago IL \\ 60611 \\ ${ }^{4}$ The University of Texas MD Anderson Cancer Center, Department of Surgical Oncology, P.O. \\ Box 301402, Houston, TX 77230 \\ ${ }^{5}$ The University of Texas MD Anderson Cancer Center, Department of Health Services Research, \\ Houston, TX 77230
}

\begin{abstract}
Purpose-Surveillance after colorectal cancer (CRC) treatment is routine, but intensive followup may offer little-to-no overall survival benefit. Given the growing population of CRC survivors, we aimed to systematically evaluate the literature for the patient perspective on 2 questions: (1) How do CRC patients perceive routine surveillance following curative treatment and what do they expect to gain from their surveillance testing or visits? (2) Which providers (specialists, nursing, primary care) are preferred by CRC survivors to guide post-treatment surveillance?

Methods-Systematic searches of PubMed MEDLINE, Embase, the CENTRAL Register of Controlled Trials, CINAHL and PsycINFO were conducted. Studies were screened for inclusion by 2 reviewers, with discrepancies adjudicated by a third reviewer. Data were abstracted and evaluated utilizing validated reporting tools (CONSORT, STROBE, CASP) appropriate to study design.
\end{abstract}

\footnotetext{
Corresponding author (for publication and reprints): George J. Chang, MD, MS, FACS, FASCRS, Chief, Colon and Rectal Surgery, Professor of Surgical Oncology; Professor of Health Services Research, Associate Medical Director, Colorectal Center; Director of Clinical Operations, Minimally Invasive and New Technologies in Oncologic Surgery Program, UT MD Anderson Cancer Center, 1400 Pressler Street, FC 17.5022, PO Box 301402, Houston, TX 77230-1402, Phone: 713-563-1875; Fax: 713-745-4926; gchang@mdanderson.org.

Compliance with Ethical Standards:

Conflicts of Interest: The authors declare that they have no conflict of interest.

Statement of human rights and the welfare of animals: This article does not contain any studies with human participants or animals performed by any of the authors.
} 
Results-3691 citations were screened, 91 full-text articles reviewed, and 23 studies included in the final review, 15 quantitative and 8 qualitative. Overall, 12 studies indicated CRC patients perceive routine surveillance positively, expecting to gain reassurance of continued disease suppression. Negative perceptions described in 6 studies included anxiety and dissatisfaction related to quality of life or psychosocial issues during follow-up. Although 5 studies supported specialist-led care, 9 studies indicated patient willingness to have follow-up with non-specialist providers (primary care or nursing).

Conclusions-Patients' perceptions of follow-up after CRC are predominantly positive, although unmet needs included psychosocial support and quality of life.

Implications for Cancer Survivors-Survivors perceived follow-up as reassuring, however, surveillance care should be more informative and focused on survivor-specific needs.

\section{Keywords}

Colorectal cancer surveillance; follow-up care; patient-centered care; survivorship

\section{INTRODUCTION}

Colorectal cancer (CRC) remains the third most common cancer in the United States.[1] With the 5-year survival rate reaching 90\% among patients with localized disease, there are an estimated 1.4 million CRC survivors in the United States.[2] This growing population of cancer survivors provides incentive for improving healthcare delivery. In 2005, the Institute of Medicine released a report to improve the care provided to cancer survivors, increasing awareness of medical, functional and psychosocial needs throughout survivorship.[3]

After curative treatment, recommended CRC surveillance varies with a combination of office visits, laboratory tests, imaging and endoscopy. With a range of different surveillance guidelines,[4-9] the optimal strategy is controversial. Receipt of follow-up care is highly variable, characterized by both over- and under-treatment. Adherence to surveillance guidelines ranges from $12 \%$ to $87 \%$.[10] Furthermore, many patients receive nonrecommended tests for metastatic disease during follow-up.[11, 12]

Surveillance aims to detect recurrence or new disease at a sufficiently early stage to facilitate curative treatment, presumably to reduce mortality. Among CRC survivors, recurrence rates vary from $10 \%$ to over 50\% dependent upon patient and tumor-related prognostic factors. [13-15] Recent evidence suggests that intensive follow-up strategies have little or no effect on overall survival, although they may detect recurrence earlier with more salvage surgery. $[15,16]$ Without a clear survival benefit, these studies call into question the current paradigm of follow-up care. Surveillance may pose risks for over-diagnosis and the need for invasive procedures. Moreover it can lead to significant anxiety. For the 1.4 million CRC survivors in the United States, intensive follow-up may detect only a small number of recurrent cases, with a smaller proportion eligible for resection and an even smaller number achieving cure.

The growing population of cancer survivors and evolving concepts of survivorship care necessitates a full understanding of patient preferences. Given the lack of clarity on optimal 
surveillance, widely variable receipt of follow-up care and a need to re-focus care on patientcentered priorities, CRC survivors can provide critical insight into surveillance care. Though systematic reviews have examined survival benefits and adherence patterns associated with colorectal cancer surveillance, there is no systematic review of the patient perspective. The aim of this systematic review was to explore the literature for 2 key patient-centered questions: (1) How do CRC patients perceive routine surveillance following curative treatment and what do they expect to gain from their surveillance testing or visits? (2) Which types of providers are preferred by survivors to guide post-treatment surveillance?

\section{METHODS}

\section{Search Strategy}

This systematic review was guided by the PRISMA (Preferred Reporting Items for Systematic Reviews and Meta-Analyses) statement. The study protocol was published online in the Prospero International prospective register of systematic reviews.[17] The search strategy was developed by study authors (JB, AC, GC, LO) and run by LO in the following databases: MEDLINE (pubmed.com), Embase (embase.com), Cochrane Central Register of Controlled Trials (CENTRAL) on the Wiley platform, CINAHL (Ebsco) and PsycINFO (Ebsco). Search strategies were adapted for each database from the MEDLINE search strategy (See Online Resource 1). All databases were searched back to their inception; no language or date limits were applied. The search included combinations of terms for colorectal cancer, patient perceptions, and surveillance or follow-up. Patient perception terms included attitudes, expectations, reactions, opinions and acceptance. Surveillance or "follow-up" focused on the receipt of surveillance monitoring, continuity of care and survivorship care for CRC patients following initial treatment.

\section{Inclusion and Exclusion Criteria}

Studies were considered eligible if they included: (1) a population of adults (age $\geq 18$ years) who had undergone treatment, including surgical resection, for CRC of all stages; (2) data on patient perceptions or expectations of care; (3) surveillance care in the form of follow-up visits, imaging, blood tests and/or colonoscopy; and (4) primary study data (not a review, editorial or commentary). Articles that focused on CRC "surveillance" or "screening" in the setting of inflammatory bowel disease, familial adenomatous polyposis or hereditary nonpolyposis CRC/Lynch syndrome were not considered eligible. Articles were excluded if they failed to provide patient perspectives on surveillance, were not about surveillance care or were abstracts only. A pilot screen of the first 100 citations from the search strategy was performed to refine criteria and ensure consistency between raters. All articles, including the first 100 , were subject to the final inclusion and exclusion criteria.

\section{Selection of Studies}

Studies were selected through a multi-step process. Two reviewers (JB and AC) independently reviewed titles and abstracts, categorizing articles as "Yes", "No" or "Maybe" with regard to full-text review. Articles marked "Yes" or "Maybe" were moved to full-text review, performed independently by both reviewers to determine final inclusion in the study. 
Discrepancies between reviewers were adjudicated through discussion until consensus was reached, or referred to a third reviewer (GC) as a tie-breaker.

\section{Data Extraction}

Two reviewers (JB and AC) extracted relevant information regarding the study country of origin, patient population, eligibility criteria, duration of follow-up, study design, analysis and results. One reviewer completed the extraction while the other verified abstracted data.

\section{Quality of Evidence}

Quality assessments were completed using standard frameworks: the CONSORT and STROBE checklists were applied to randomized and observational studies, respectively; qualitative articles were assessed according to criteria on the CASP tool.[18] Using the STROBE and CONSORT checklist, studies were assessed for completeness of reporting on each element, rating each according to the following criteria: "yes, explicitly reported by study authors," "inferred by raters but not explicitly reported by study authors" or "no, not reported by study authors." Using the CASP tool, there were 9 components assessed according to: "yes," "raters unable to determine" or "no".

\section{RESULTS}

Searches returned a total of 3691 articles for title/abstract screen, with 91 selected for fulltext review; 23 studies[19-41] were included in the final review (Fig. 1). These latter included 15 quantitative and 8 qualitative studies conducted across the United States (3 studies), United Kingdom (8), Italy (2), Denmark (1), Netherlands (2), Sweden (1), Canada (3) and Australia (3), (Table 1). Among the 15 quantitative studies, the most common research design was a cross-sectional survey $(\mathrm{n}=10)$. Among the 8 qualitative studies, 4 utilized semi-structured interviews. The 23 studies were published between 1997 and 2014. All included CRC patients who had undergone treatment, with 4 studies including other cancer types.

\section{Quality of Evidence}

There was variability in the quality of evidence across studies. Of the 15 quantitative studies, 13 were observational studies assessed with the STROBE checklist. These ranged in quality from low (5 of 22 STROBE elements) to high (21 of 22). Two randomized trials were assessed with the CONSORT checklist; both reported 16 of 22 CONSORT elements. The 8 qualitative studies were assessed with the CASP tool, ranging in quality from low (5 of 9 CASP elements) to high (9 of 9). The most consistent weakness among the qualitative studies was lack of consideration regarding the relationship between the researcher and the participants (7 studies). (See Online Resource 2)

\section{Question 1: Patient Perceptions of Routine Surveillance}

Sixteen studies provided information regarding patient perceptions and expectations of routine surveillance after treatment for CRC. Findings pertaining to both positive and negative perceptions of surveillance are summarized in Table 2 . 
Twelve (75\%) of the 16 studies identified positive perceptions of CRC surveillance. Positive perceptions included high rates of overall satisfaction with follow-up care[19, 31, 32, 36], with one study identifying a correlation between longer patient-physician relationship and perceived quality of follow-up care[19]. Compared to an infrequent follow-up group, patients with more frequent follow up visits had greater confidence in the visits and believed that such follow-up care could improve survival[28]. The majority of patients believed that evaluation for recurrence was the most important reason for follow up[25, 32]. Patients valued receipt of tangible information regarding their disease and surveillance[22, 39], and desired providers to review the information with them, including the nature of tests and frequency of visits[39]. When examined, issues of access to care and frequency of visits were satisfactory[19, 31, 36].

Several articles emphasized that patients receive emotional reassurance from follow-up[24, $28,31,33-36]$. Followup tests that confirmed the absence of disease were highly valued, described in one qualitative study as "better than winning the lottery"[33]. Most patients reported no more anxiety than usual the week before a visit[31]; fear and worry over followup testing was rare[34, 35].

Several studies directly compared the potential stressors of follow-up to the benefits, finding that the stress and anxiety of follow-up tests was perceived as minimal for the benefit received by routine surveillance visits[24, 31, 34, 36]. In a study focused on Carcinoembryonic antigen (CEA) testing, patients explicitly wanted to continue tests despite the possibility of false positive results, and stated they would want to be informed of a recurrence even if it were incurable[34]. Similarly, patients reported a desire to continue regular follow-up visits with their physician regardless of survival benefit and wished to be informed of a recurrence, even if there were no survival or treatment benefit offered[31].

Six (37.5\%) of the 16 studies described negative perceptions of follow-up. These included anxiety or stress related to follow-up visits or tests, unmet expectations regarding information exchange, lack of psychosocial evaluation and emotional support and overall dissatisfaction. Patients felt they were not encouraged to ask questions and did not receive satisfactory answers, with most noting that physicians lack knowledge of how CRC affects quality of life[19]. Patients were dissatisfied with available information regarding how treatment would affect their body and sexuality, communication between providers and the extent to which their family was included and considered in care planning[22]. Some patients experienced anxiety and stress associated with follow-up[29, 33]; concern over cancer recurrence was worse among patients with young children[34]. Patients often displayed a state of "guarding" associated with anxiety about recurrence, loss of confidence in health and perceived loss of control over one's body[38]. Patients felt that evaluating unpleasant emotional states (including anxiety, restlessness and depression) was an important part of follow-up, a priority not shared among surgeons[25]. Though the majority of patients wanted counselling from their physicians, only a minority received such counselling[30]. 


\section{Question 2: Patient Preference for Delivery of Surveillance by Provider-Type}

The question of surveillance care delivery was addressed by 14 studies (Fig. 2). There were 8 quantitative and 6 qualitative study designs, and study findings for this set were heterogeneous. Studies addressed the perceived role of the following 3 provider-types: specialist nurse, the general (GP) or family practitioner (FP) or the specialist (surgeon or oncologist). None suggested complete exclusion of the specialist. Five studies suggested patients were open to or supportive of nurse-led follow-up.[20-23, 37] Benefits to nurse-led follow up included improved access to care, continuity, patient education and perceived support in coping with their disease.[21, 23] Four studies suggested willingness to engage the GP or FP in a larger role in follow-up[26, 27, 33, 40]. This was particularly favored among patients who endorsed a strong patient-physician relationship with their GPs[33], however, some patients expressed concern about losing contact with specialists [27]. Finally, 5 studies demonstrated a preference for specialists[31, 35, 36, 39, 41]. Regardless of having an engaged GP or FP, patients found comfort in the authority and expertise associated with specialist care[39]. Patient satisfaction with follow-up was generally high regardless of the type of provider delivering surveillance care.

There were 3 studies examining quality of life (QOL) as an outcome[26, 36, 40] and one examining healthcare resource utilization and patient safety[37]. Frequency and timing of follow-up visits did not affect QOL[36]. Comparing GP-led and surgeon-led follow-up, there was no difference in health-related quality of life, anxiety or depression[26, 40]. Compared to surgeon-led follow-up, nurse-led follow up was associated with longer consultation times and more blood tests, though there was no difference in radiologic studies ordered[37].

\section{DISCUSSION}

Post-treatment CRC surveillance monitors patients for the development of recurrence, promotes prevention and health maintenance, and provides important emotional and psychosocial support. The 23 articles identified in this systematic review offered insight into patient perspectives on surveillance after CRC treatment. The articles originated from a diverse range of countries using a variety of methodologies. Overall, positive perceptions predominated, with follow-up providing emotional reassurance of being cancer-free. Patients reported high satisfaction with follow-up and believed that continued follow-up was important for the detection of recurrence. There were widely variable preferences for a given type of provider to conduct follow-up surveillance; however, satisfaction was generally high regardless of care by specialists, primary care providers or nurse specialists.

Reassessing the patient perspective on survivorship and follow-up has wide-reaching, international importance. In the United States, the Patient-Centered Outcomes Research Institute (PCORI) places emphasis on patient-centered clinical comparative effectiveness research. Three studies from the United States[19, 32, 35] were included in this review, all demonstrating positive perceptions of surveillance care, with two of the three identifying room for improvement in patient education and information exchange[32, 35]. The National Health Service in the United Kingdom begins its manual on CRC services with a chapter concerning patient-centered care.[42] This review included eight studies from the United 
Kingdom[21-23, 27, 31, 33, 34, 38], with findings that reflect a wide range of patientperspectives, from the positive role of reassurance[31] to the anxieties and guarding experienced by survivors[38]. A Canadian report called for better identifying survivors' needs during follow-up, developing and implementing appropriate models for care and increasing collaboration between the healthcare system and the community.[43] Three Canadian studies [24, 30, 39] underscore the positive importance of follow-up for CRC survivors and the need to improve patient education. Given high survival rates and an aging global population, many countries have responded with a renewed focus on the patient.

The optimal follow-up strategy after treatment for CRC remains controversial. A 2016 Cochrane systematic review of 5403 CRC patients in 15 randomized controlled trials found that despite more salvage surgery with intensive follow-up, there was no significant difference in overall or relapse-free survival compared with less-intense followup.[16] From the specialist provider's perspective, follow-up for the detection of local recurrence or distant metastasis may not be justified if increased intervention has no effect on survival. In contrast, the patient perceives follow-up for a complimentary, but not identical, purposeconfirmation of a disease-free state, the value of which extends beyond survival alone. Primary care providers and specialist nurses could potentially bridge this gap, however, there is considerable variability in perceived roles and responsibilities among PCPs and specialists regarding surveillance care[44]. A survey of cancer specialists in Canada found that at least half believed primary care providers may better deliver psychosocial support for colorectal cancer survivors[45]. In a nationally-representative US sample, approximately half of oncologists and primary care providers self-report providing broad psychosocial care to cancer survivors, however, both groups saw themselves as the main providers[46]. Beyond the need to educate providers, improved survivorship care will require better coordination and delineation of different roles in multidisciplinary management. Furthermore, this review identified variability in preferences for specialist, nurse and GP-led surveillance, yet persistently high rates of satisfaction for different provider-types across studies. Opportunities for future work exist in educating patients about the potential roles for multiple different provider-types and further evaluating patient perspectives on their followup needs. Research on decision-making interventions must incorporate patient perspectives, as tools that rely solely on the likelihood of recurrence and potential for cure may inadequately address survivorship needs.

The follow-up visit presents an opportunity to fulfill unmet patient needs after treatment for CRC. Beyond reassurance that patients remain cancer-free, the visit provides an opportunity for education, rather than delivery of a binary answer. Many patients are unaware how recurrence risk changes over time. For example, conditional survival of stage IIIC colon cancer improves dramatically from $42 \%$ to $80 \%$ over the first 5 post-treatment years,[47] with similar improvements in rectal cancer[48]. This review identified room for improvement in information exchange, sensitivity toward psychosocial and quality of life issues and emphasis on general health maintenance and prevention. Failure to address psychosocial concerns can have significant health consequences on depression and anxiety[49], quality of life[50], adherence to recommended surveillance protocols[51] and even survival[52-54]. The Institute of Medicine has highlighted psychosocial care as a critical component of survivorship care[3] and subsequently produced important guidance 
on the development and implementation of survivorship care plans[55]. Key areas for improvement at the provider-level may include better coordination in follow-up visits, utilizing multidisciplinary healthcare professionals to implement screening for psychosocial distress, and better tailoring follow-up care to the individual patient[56]. Further advances may require engagement of professional organizations in developing and disseminating coordinated efforts such as best practice guidelines.[57] Finally, incorporating patientpriorities into survivorship care demands continued focus on better understanding patientperspectives. This review identified studies with wide-ranging quantitative and qualitative methodologies, however, many quantitative studies focused predominantly on satisfaction and quality of life. The field of survivorship care, including its related literature, may benefit from research that expands beyond these concepts, reaching to improve processes of care (e.g., individualized decision support tools) and outcomes that matter most to patients (e.g., patient-reported outcomes). Focusing on patient-centered priorities may provide new purpose for routine follow-up care in the face of equivocal survival outcomes.

This study has several limitations. First, the generalizability of these findings across healthcare systems is uncertain. Single vs multi-payer systems differ significantly in the distribution of costs; single-payer systems have greater incentive to maximize the role of primary or nursing care. Hence, our findings related to patient preferences for a given provider-type may have less direct relevance in the United States, where not all patients have access to primary care. Second, patient perspectives are subjective endpoints, posing a challenge to the reproducibility of our review. We attempted to minimize bias with the development of a review protocol,[17] and by conducting the review in duplicate. Third, use of qualitative studies in a systematic review is challenging. Despite debate, qualitative studies can provide critical data otherwise unrepresented through quantitative methodologies.[58-60]

In conclusion, this systematic review indicates that CRC patients hold a positive view of follow-up care as a mechanism to provide reassurance. However, there is a persistent need to improve patient-centeredness by enhancing communication about the expectations for surveillance and increasing sensitivity to psychosocial and quality of life concerns.

\section{Acknowledgments}

Funding sources: This work was supported, in part, by the Patient-Centered Outcomes Research Institute (PCORI), Award [CE13-04-6855, GJC]. The content is the responsibility of the authors and does not represent the views of PCORI, its Board of Governors or Methodology Committee. This work was also supported, in part, by the National Cancer Institute of the National Institutes of Health under the Award Number(s) UG1CA189823 to the Alliance for Clinical Trials in Oncology NCORP Research Base (Jan C. Buckner, M.D., contact PI). The content is the responsibility of the authors and does not represent the views of the National Institutes of Health. This work was also supported, in part, by a grant from The University of Texas MD Anderson Cancer Center's Duncan Family Institute for Cancer Prevention and Risk Assessment. Dr. Berian's position is funded by the John A. Hartford Foundation and American College of Surgeons.

\section{References}

1. Siegel R, Desantis C, Jemal A. Colorectal cancer statistics, 2014. CA Cancer J Clin. 2014; 64(2): 104-17. [PubMed: 24639052]

2. Miller KD, Siegel RL, Lin CC, Mariotto AB, Kramer JL, Rowland JH, et al. Cancer treatment and survivorship statistics, 2016. CA Cancer J Clin. 2016; 66(4):271-89. [PubMed: 27253694] 
3. Hewitt, ME., Greenfield, S., Stovall, E., National Cancer Policy Board (U.S.). Committee on Cancer Survivorship: Improving Care and Quality of Life From Cancer Patient to Cancer Survivor : Lost in Transition. Washington, D.C: National Academies Press; 2006.

4. Steele SR, Chang GJ, Hendren S, Weiser M, Irani J, Buie WD, et al. Practice Guideline for the Surveillance of Patients After Curative Treatment of Colon and Rectal Cancer. Diseases of the colon and rectum. 2015; 58(8):713-25. [PubMed: 26163950]

5. Rex DK, Kahi CJ, Levin B, Smith RA, Bond JH, Brooks D, et al. Guidelines for colonoscopy surveillance after cancer resection: a consensus update by the American Cancer Society and US Multi-Society Task Force on Colorectal Cancer. CA Cancer J Clin. 2006; 56(3):160-7. quiz 85-6. [PubMed: 16737948]

6. Figueredo A, Rumble RB, Maroun J, Earle CC, Cummings B, McLeod R, et al. Follow-up of patients with curatively resected colorectal cancer: a practice guideline. BMC Cancer. 2003; 3:26. [PubMed: 14529575]

7. Meyerhardt JA, Mangu PB, Flynn PJ, Korde L, Loprinzi CL, Minsky BD, et al. Follow-up care, surveillance protocol, and secondary prevention measures for survivors of colorectal cancer: American Society of Clinical Oncology clinical practice guideline endorsement. Journal of clinical oncology : official journal of the American Society of Clinical Oncology. 2013; 31(35):4465-70. [PubMed: 24220554]

8. Benson AB 3rd, Venook AP, Bekaii-Saab T, Chan E, Chen YJ, Cooper HS, et al. Colon cancer, version 3.2014. Journal of the National Comprehensive Cancer Network : JNCCN. 2014; 12(7): 1028-59. [PubMed: 24994923]

9. Benson AB 3rd, Venook AP, Bekaii-Saab T, Chan E, Chen YJ, Cooper HS, et al. Rectal Cancer, Version 2.2015. Journal of the National Comprehensive Cancer Network : JNCCN. 2015; 13(6): 719-28. quiz 28. [PubMed: 26085388]

10. Carpentier MY, Vernon SW, Bartholomew LK, Murphy CC, Bluethmann SM. Receipt of recommended surveillance among colorectal cancer survivors: a systematic review. J Cancer Surviv. 2013; 7(3):464-83. [PubMed: 23677524]

11. Salloum RG, Hornbrook MC, Fishman PA, Ritzwoller DP, O’Keeffe Rossetti MC, Elston Lafata J. Adherence to surveillance care guidelines after breast and colorectal cancer treatment with curative intent. Cancer. 2012; 118(22):5644-51. [PubMed: 22434568]

12. Bailey CE, Hu CY, You YN, Kaur H, Ernst RD, Chang GJ. Variation in positron emission tomography use after colon cancer resection. J Oncol Pract. 2015; 11(3):e363-72. [PubMed: 25852143]

13. Gill S, Loprinzi CL, Sargent DJ, Thome SD, Alberts SR, Haller DG, et al. Pooled analysis of fluorouracil-based adjuvant therapy for stage II and III colon cancer: who benefits and by how much? Journal of clinical oncology : official journal of the American Society of Clinical Oncology. 2004; 22(10):1797-806. [PubMed: 15067028]

14. Sargent DJ, Wieand HS, Haller DG, Gray R, Benedetti JK, Buyse M, et al. Disease-free survival versus overall survival as a primary end point for adjuvant colon cancer studies: individual patient data from 20,898 patients on 18 randomized trials. Journal of clinical oncology : official journal of the American Society of Clinical Oncology. 2005; 23(34):8664-70. [PubMed: 16260700]

15. Tjandra JJ, Chan MK. Follow-up after curative resection of colorectal cancer: a meta-analysis. Diseases of the colon and rectum. 2007; 50(11):1783-99. [PubMed: 17874269]

16. Jeffery M, Hickey BE, Hider PN, See AM. Follow-up strategies for patients treated for nonmetastatic colorectal cancer. The Cochrane database of systematic reviews. 2016; 11:CD002200. [PubMed: 27884041]

17. Berian, JR., Cuddy, A., Chang, GJ. Patient preferences related to routine surveillance following treatment for colorectal cancer. PROSPERO. 2016. CRD42016042482 Available at http:// www.crd.york.ac.uk/PROSPERO/display_record.asp?ID=CRD42016042482

18. Critical Appraisal Skills Programme (CASP). CASP Checklists. Oxford; 2014. (http://www.caspuk.net/)

19. Arora NK, Reeve BB, Hays RD, Clauser SB, Oakley-Girvan I. Assessment of quality of cancerrelated follow-up care from the cancer survivor's perspective. J Clin Oncol. 2011; 29(10):1280-9. [PubMed: 21357781] 
20. Baravelli C, Krishnasamy M, Pezaro C, Schofield P, Lotfi-Jam K, Rogers M, et al. The views of bowel cancer survivors and health care professionals regarding survivorship care plans and post treatment follow up. J Cancer Surviv. 2009; 3(2):99-108. [PubMed: 19415504]

21. Beaver K, Latif S, Williamson S, Procter D, Sheridan J, Heath J, et al. An exploratory study of the follow-up care needs of patients treated for colorectal cancer. J Clin Nurs. 2010; 19(23-24):3291300. [PubMed: 20964750]

22. Beaver K, Wilson C, Procter D, Sheridan J, Towers G, Heath J, et al. Colorectal cancer followup: patient satisfaction and amenability to telephone after care. Eur J Oncol Nurs. 2011; 15(1):23-30. [PubMed: 20584628]

23. Browne S, Dowie A, Mitchell E, Wyke S, Ziebland S, Campbell N, et al. Patients' needs following colorectal cancer diagnosis: where does primary care fit in? The British journal of general practice : the journal of the Royal College of General Practitioners. 2011; 61(592):e692-9. [PubMed: 22054330]

24. Cardella J, Coburn NG, Gagliardi A, Maier BA, Greco E, Last L, et al. Compliance, attitudes and barriers to post-operative colorectal cancer follow-up. J Eval Clin Pract. 2008; 14(3):407-15. [PubMed: 18373578]

25. Di Fabio F, Koller M, Nascimbeni R, Talarico C, Salerni B. Long-term outcome after colorectal cancer resection. Patients' self-reported quality of life, sexual dysfunction and surgeons' awareness of patients' needs. Tumori. 2008; 94(1):30-5. [PubMed: 18468332]

26. Gall CA, Weller D, Esterman A, Pilotto L, McGorm K, Hammett Z, et al. Patient satisfaction and health-related quality of life after treatment for colon cancer. Diseases of the colon and rectum. 2007; 50(6):801-9. [PubMed: 17285234]

27. Hall SJ, Samuel LM, Murchie P. Toward shared care for people with cancer: developing the model with patients and GPs. Family practice. 2011; 28(5):554-64. [PubMed: 21467132]

28. Kjeldsen BJ, Thorsen H, Whalley D, Kronborg O. Influence of follow-up on health-related quality of life after radical surgery for colorectal cancer. Scandinavian journal of gastroenterology. 1999; 34(5):509-15. [PubMed: 10423068]

29. Li Destri G, Sapienza S, Rodolico M, Di Cataldo A, Puleo S, Minutolo V, et al. Stress of routine follow-up in colorectal cancer operated patients. Chirurgia italiana. 2000; 52(6):695-8. [PubMed: 11200005]

30. Miedema B, MacDonald I, Tatemichi S. Cancer follow-up care: Patients' perspective. Canadian Family Physician. 2003 Jul.49:890-5. [PubMed: 12901486]

31. Papagrigoriadis S, Heyman B. Patients' views on follow up of colorectal cancer: implications for risk communication and decision making. Postgrad Med J. 2003; 79(933):403-7. [PubMed: 12897220]

32. Pisu M, Holt CL, Brown-Galvan A, Fairley T, Smith JL, White A, et al. Surveillance instructions and knowledge among African American colorectal cancer survivors. J Oncol Pract. 2014; 10(2):e45-50. [PubMed: 24385336]

33. Rozmovits L, Rose P, Ziebland S. In the absence of evidence, who chooses? A qualitative study of patients' needs after treatment for colorectal cancer. J Health Serv Res Policy. 2004; 9(3):159-64. [PubMed: 15272974]

34. Steele N, Haigh R, Knowles G, Mackean M. Carcinoembryonic antigen (CEA) testing in colorectal cancer follow up: what do patients think? Postgraduate medical journal. 2007; 83(983):612-4. [PubMed: 17823231]

35. Sterba KR, Zapka J, LaPelle N, Armeson K, Ford ME. A Formative Study of Colon Cancer Surveillance Care: Implications for Survivor-Centered Interventions. Journal of cancer education : the official journal of the American Association for Cancer Education. 2014

36. Stiggelbout AM, de Haes JC, Vree R, van de Velde CJ, Bruijninckx CM, van Groningen K, et al. Follow-up of colorectal cancer patients: quality of life and attitudes towards follow-up. Br J Cancer. 1997; 75(6):914-20. [PubMed: 9062416]

37. Strand E, Nygren I, Bergkvist L, Smedh K. Nurse or surgeon follow-up after rectal cancer: a randomized trial. Colorectal Dis. 2011; 13(9):999-1003. [PubMed: 20478003] 
38. Taylor C, Richardson A, Cowley S. Surviving cancer treatment: an investigation of the experience of fear about, and monitoring for, recurrence in patients following treatment for colorectal cancer. Eur J Oncol Nurs. 2011; 15(3):243-9. [PubMed: 21530395]

39. Urquhart R, Folkes A, Babineau J, Grunfeld E. Views of breast and colorectal cancer survivors on their routine follow-up care. Curr Oncol. 2012; 19(6):294-301. [PubMed: 23300354]

40. Wattchow DA, Weller DP, Esterman A, Pilotto LS, McGorm K, Hammett Z, et al. General practice vs surgical-based follow-up for patients with colon cancer: randomised controlled trial. Br J Cancer. 2006; 94(8):1116-21. [PubMed: 16622437]

41. Wind J, Duineveld LA, van der Heijden RP, van Asselt KM, Bemelman WA, van Weert HC. Follow-up after colon cancer treatment in the Netherlands; a survey of patients, GPs, and colorectal surgeons. European journal of surgical oncology : the journal of the European Society of Surgical Oncology and the British Association of Surgical Oncology. 2013; 39(8):837-43.

42. National Institute for Clinical Excellence: Improving Outcomes in Colorectal Cancers, Manual Update. 2004

43. Ristovski-Slijepcevic, S. Environmental Scan of Cancer Survivorship in Canada: Conceptualization, Practice and Research. Agency, BC., editor. Vancouver, BC: 2008.

44. Zapka J, Sterba KR, LaPelle N, Armeson K, Burshell DR, Ford ME. Physician perspectives on colorectal cancer surveillance care in a changing environment. Qual Health Res. 2015; 25(6):83144. [PubMed: 25878188]

45. Earle CC, Grunfeld E, Coyle D, Cripps MC, Stern HS. Cancer physicians' attitudes toward colorectal cancer follow-up. Annals of oncology : official journal of the European Society for Medical Oncology / ESMO. 2003; 14(3):400-5.

46. Forsythe LP, Alfano CM, Leach CR, Ganz PA, Stefanek ME, Rowland JH. Who provides psychosocial follow-up care for post-treatment cancer survivors? A survey of medical oncologists and primary care physicians. Journal of clinical oncology : official journal of the American Society of Clinical Oncology. 2012; 30(23):2897-905. [PubMed: 22778322]

47. Chang GJ, Hu CY, Eng C, Skibber JM, Rodriguez-Bigas MA. Practical application of a calculator for conditional survival in colon cancer. Journal of clinical oncology : official journal of the American Society of Clinical Oncology. 2009; 27(35):5938-43. [PubMed: 19805670]

48. Bowles TL, Hu CY, You NY, Skibber JM, Rodriguez-Bigas MA, Chang GJ. An individualized conditional survival calculator for patients with rectal cancer. Diseases of the colon and rectum. 2013; 56(5):551-9. [PubMed: 23575393]

49. Deimling GT, Bowman KF, Sterns S, Wagner LJ, Kahana B. Cancer-related health worries and psychological distress among older adult, long-term cancer survivors. Psychooncology. 2006; 15(4):306-20. [PubMed: 16041841]

50. Stark D, Kiely M, Smith A, Velikova G, House A, Selby P. Anxiety disorders in cancer patients: their nature, associations, and relation to quality of life. Journal of clinical oncology : official journal of the American Society of Clinical Oncology. 2002; 20(14):3137-48. [PubMed: 12118028]

51. Le D, Holt CL, Pisu M, Brown-Galvan A, Fairley TL, Lee Smith J, et al. The role of social support in posttreatment surveillance among African American survivors of colorectal cancer. J Psychosoc Oncol. 2014; 32(3):245-63. [PubMed: 24611486]

52. Giese-Davis J, Collie K, Rancourt KM, Neri E, Kraemer HC, Spiegel D. Decrease in depression symptoms is associated with longer survival in patients with metastatic breast cancer: a secondary analysis. Journal of clinical oncology : official journal of the American Society of Clinical Oncology. 2011; 29(4):413-20. [PubMed: 21149651]

53. Pinquart M, Duberstein PR. Depression and cancer mortality: a meta-analysis. Psychol Med. 2010; 40(11):1797-810. [PubMed: 20085667]

54. Satin JR, Linden W, Phillips MJ. Depression as a predictor of disease progression and mortality in cancer patients: a meta-analysis. Cancer. 2009; 115(22):5349-61. [PubMed: 19753617]

55. Hewitt, M., Ganz, PA., Institute of Medicine. Implementing Cancer Survivorship Care Planning. Washington, DC: The National Academies Press; 2007. p. 320

56. McDowell ME, Occhipinti S, Ferguson M, Dunn J, Chambers SK. Predictors of change in unmet supportive care needs in cancer. Psychooncology. 2010; 19(5):508-16. [PubMed: 19598292] 
57. Jacobsen PB. Clinical practice guidelines for the psychosocial care of cancer survivors: current status and future prospects. Cancer. 2009; 115(18 Suppl):4419-29. [PubMed: 19731353]

58. Campbell M, Fitzpatrick R, Haines A, Kinmonth AL, Sandercock P, Spiegelhalter D, et al. Framework for design and evaluation of complex interventions to improve health. Bmj. 2000; 321(7262):694-6. [PubMed: 10987780]

59. Dixon-Woods M, Fitzpatrick R, Roberts K. Including qualitative research in systematic reviews: opportunities and problems. J Eval Clin Pract. 2001; 7(2):125-33. [PubMed: 11489038]

60. Dixon-Woods M, Fitzpatrick R. Qualitative research in systematic reviews. Has established a place for itself. Bmj. 2001; 323(7316):765-6. [PubMed: 11588065] 


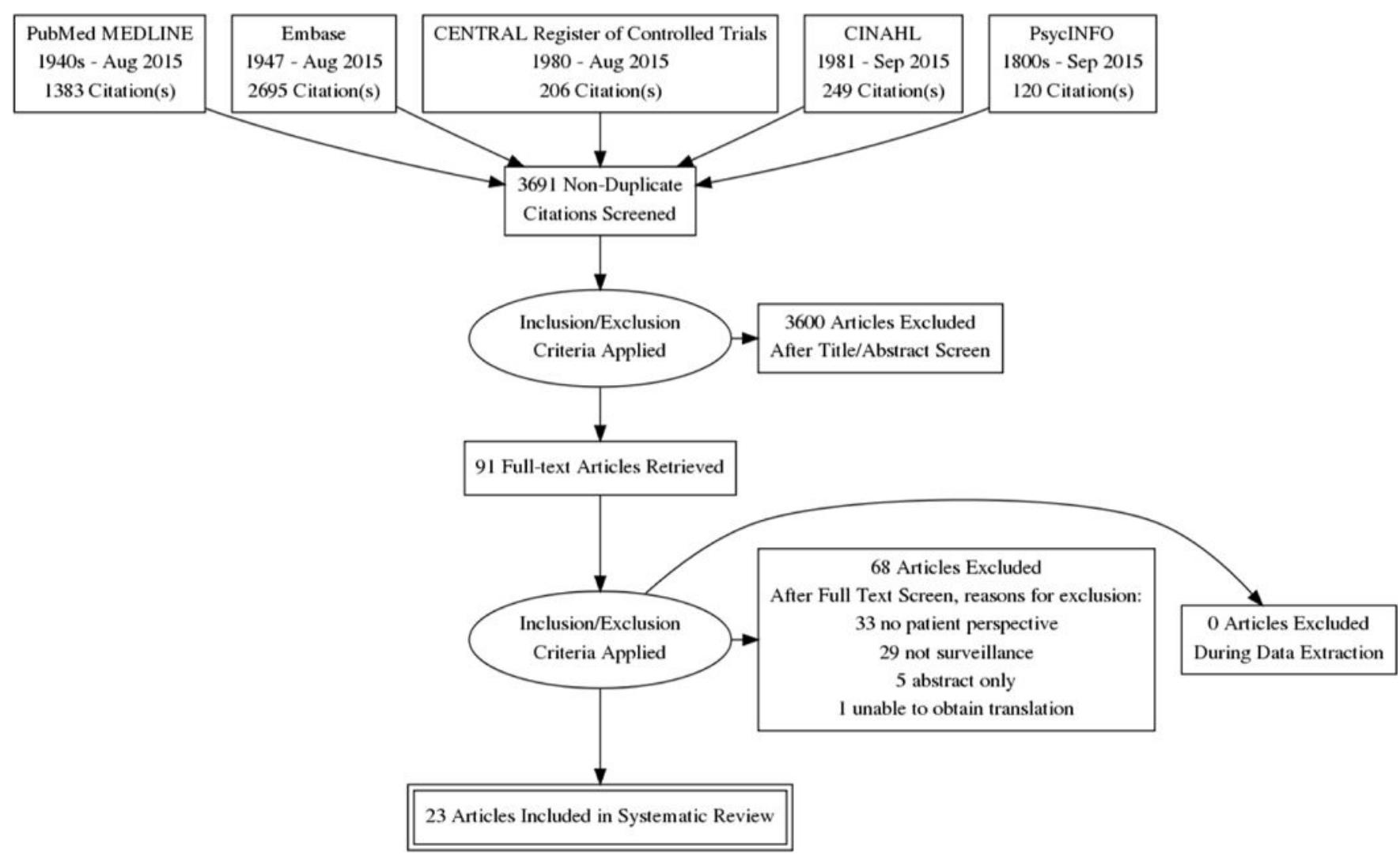

Figure 1.

Flowchart.

Search criteria were applied to PubMed MEDLINE, Embase, CENTRAL, CINAHL and PsycINFO for a total of 3691 citations. The titles/abstracts were screened, with 91 articles selected for full-text review, and 23 articles included in the final review. 


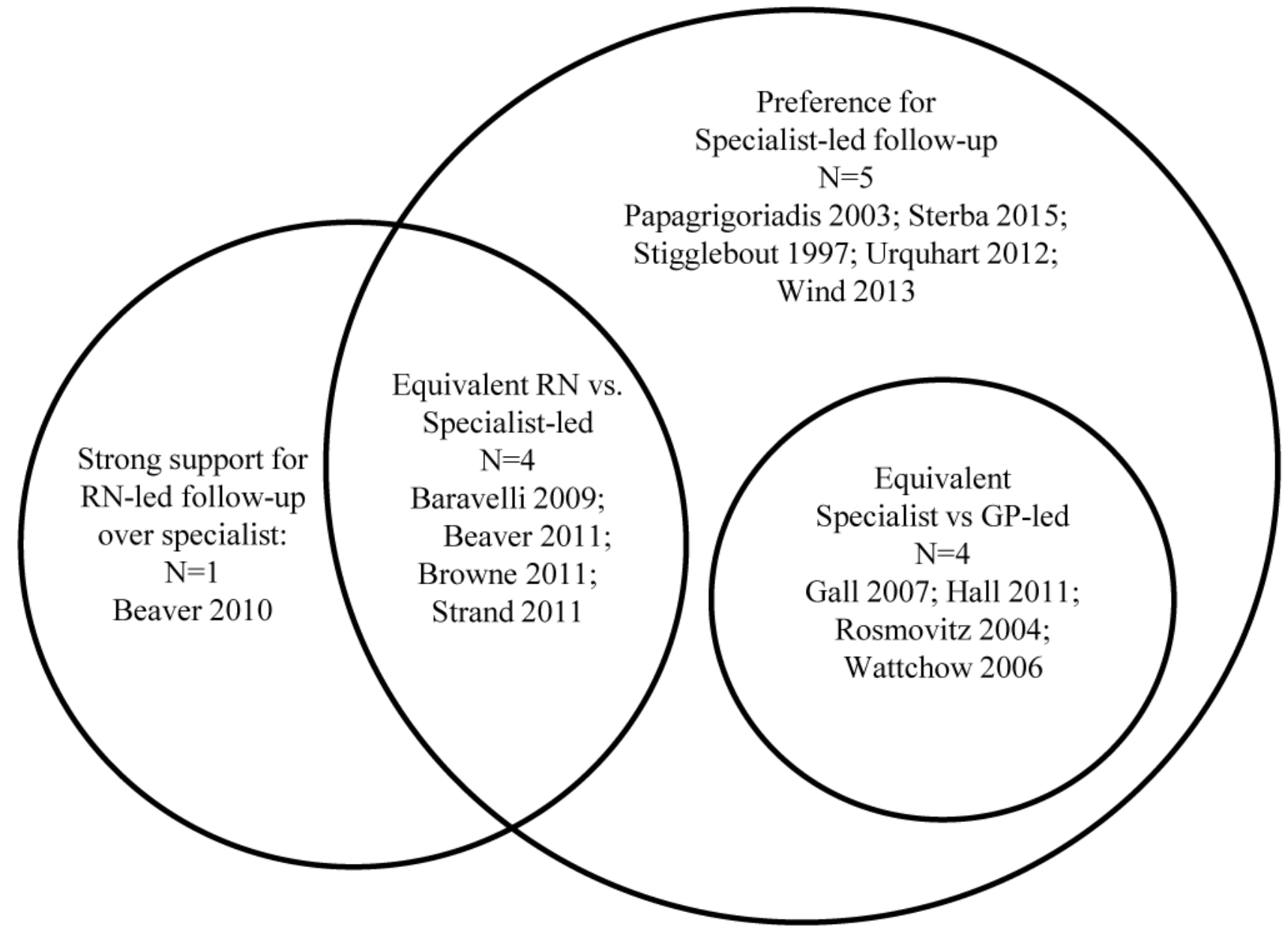

Figure 2.

Patient preferences on provider-type delivering surveillance care.

Fourteen articles addressed preferred provider-type to guide post-treatment surveillance: specialists (including surgeons and oncologists), primary care providers or general practitioners (GPs), and nurses or nurse-specialists (RNs) 


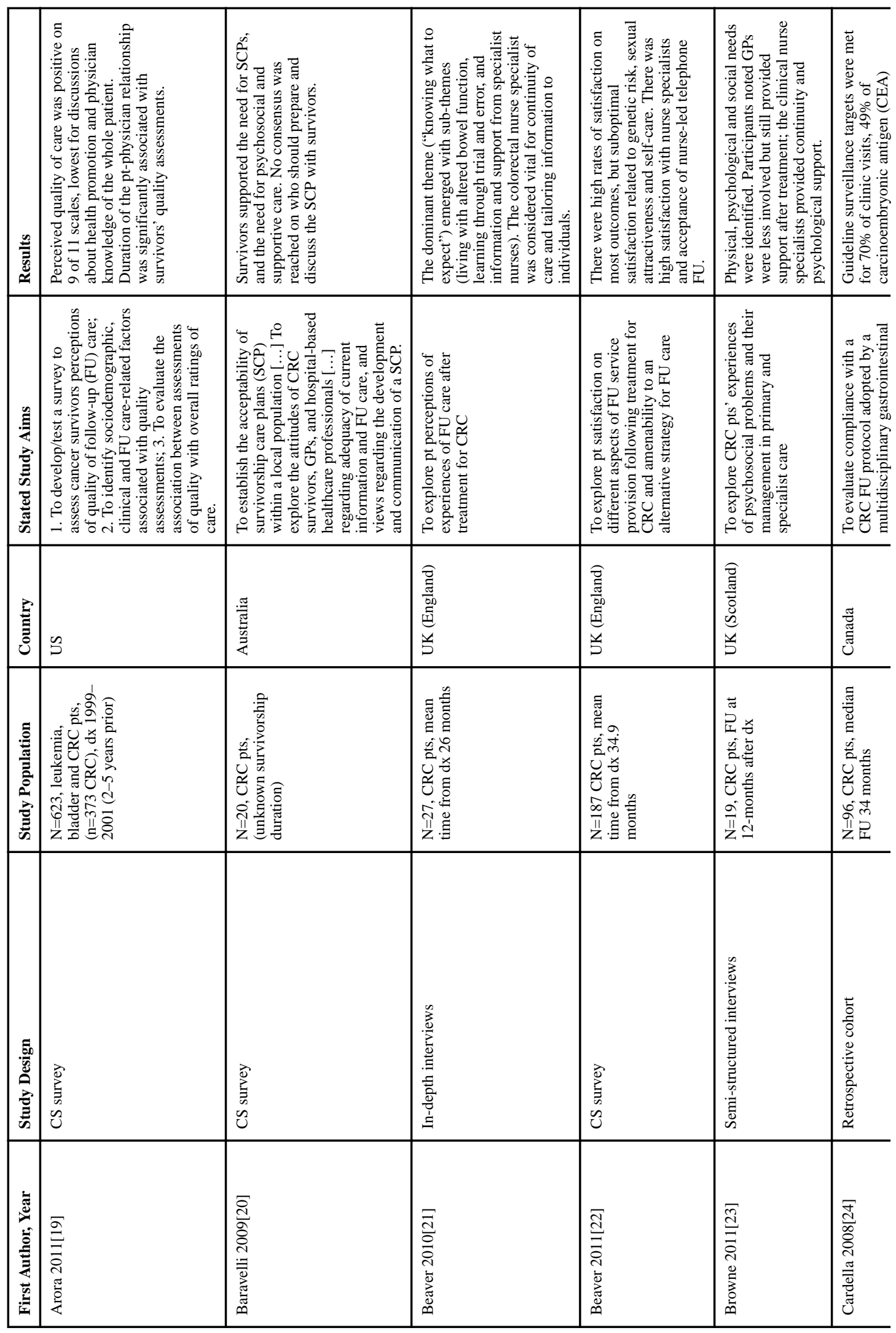

J Cancer Surviv. Author manuscript; available in PMC 2018 October 01. 


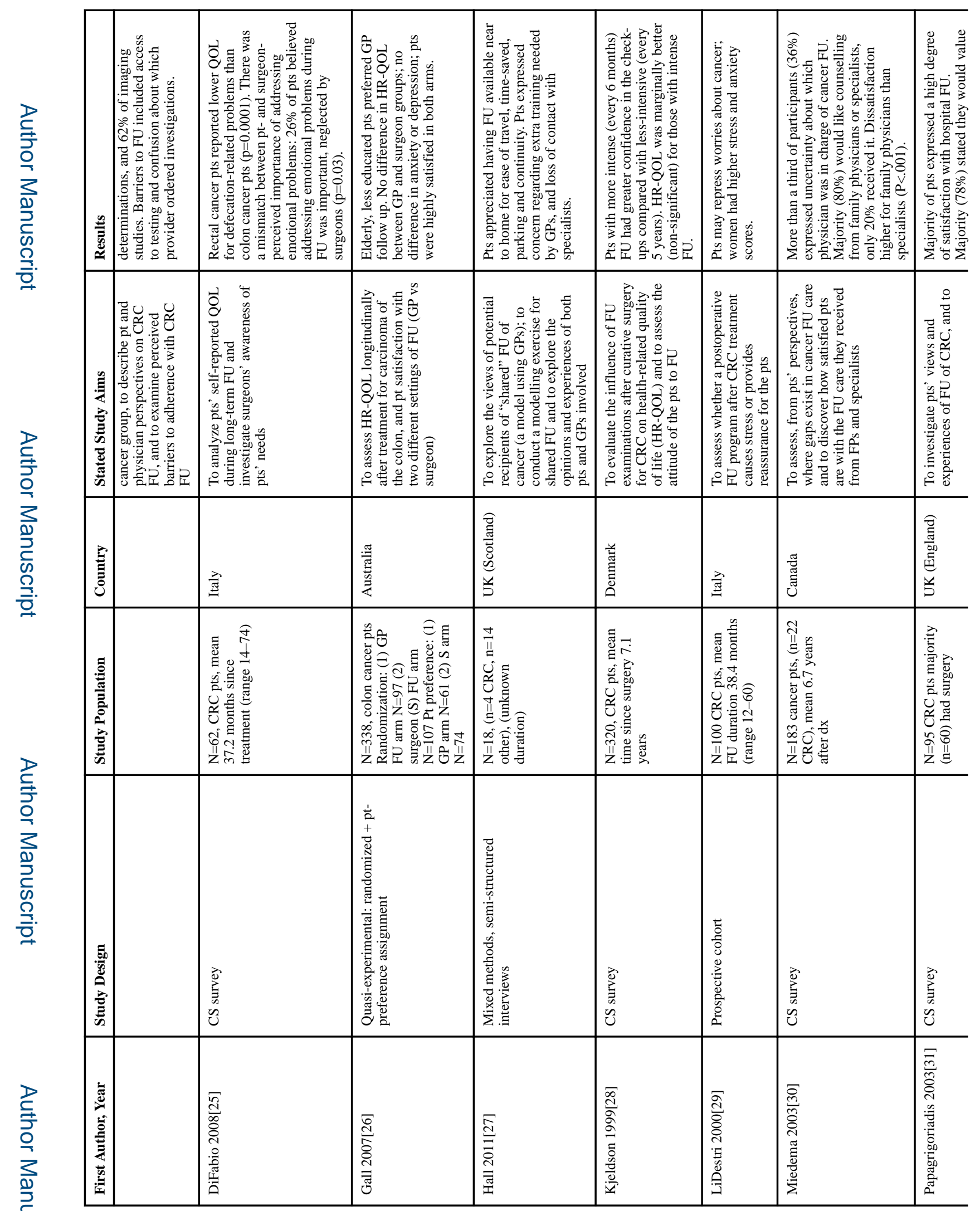

J Cancer Surviv. Author manuscript; available in PMC 2018 October 01. 


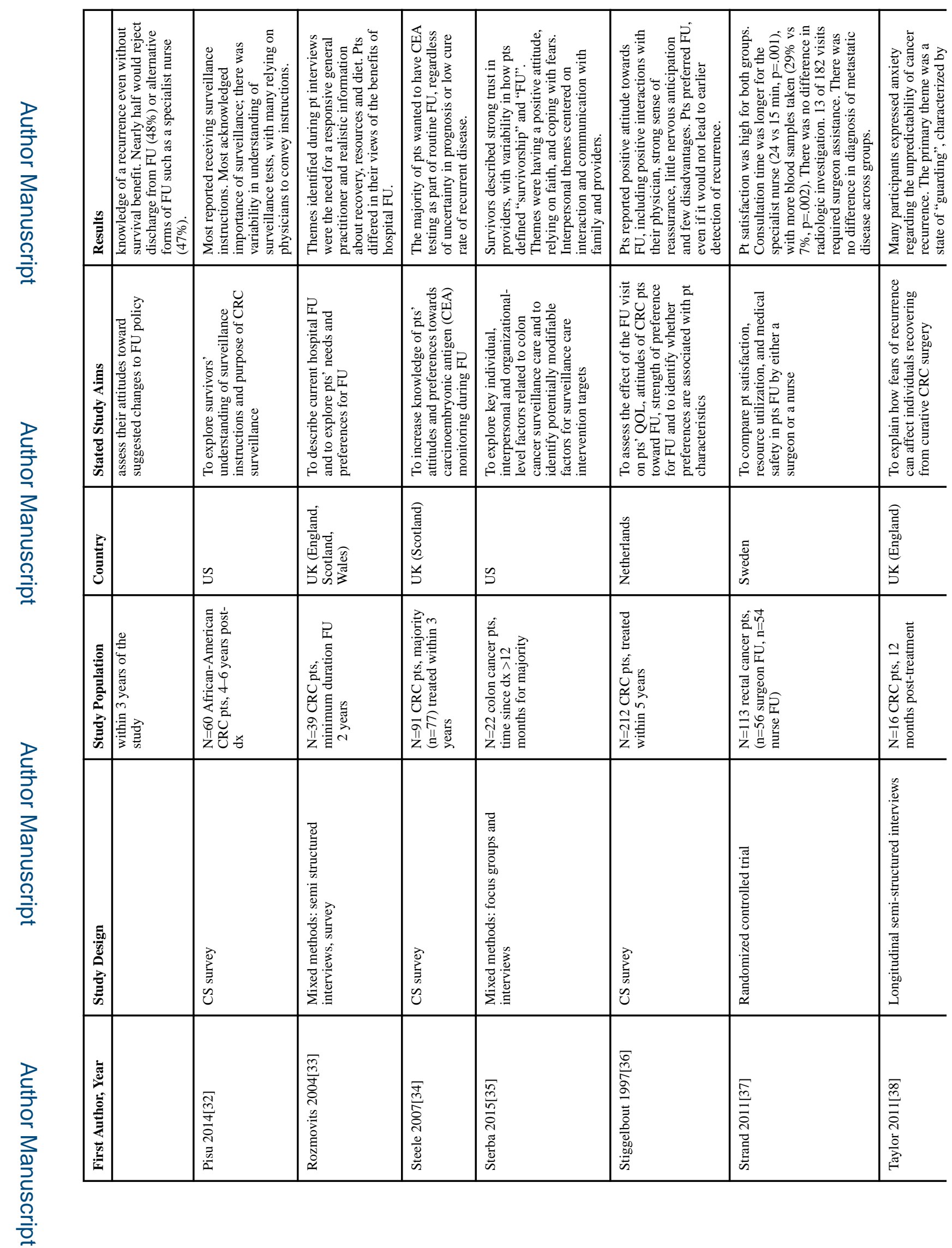

J Cancer Surviv. Author manuscript; available in PMC 2018 October 01. 


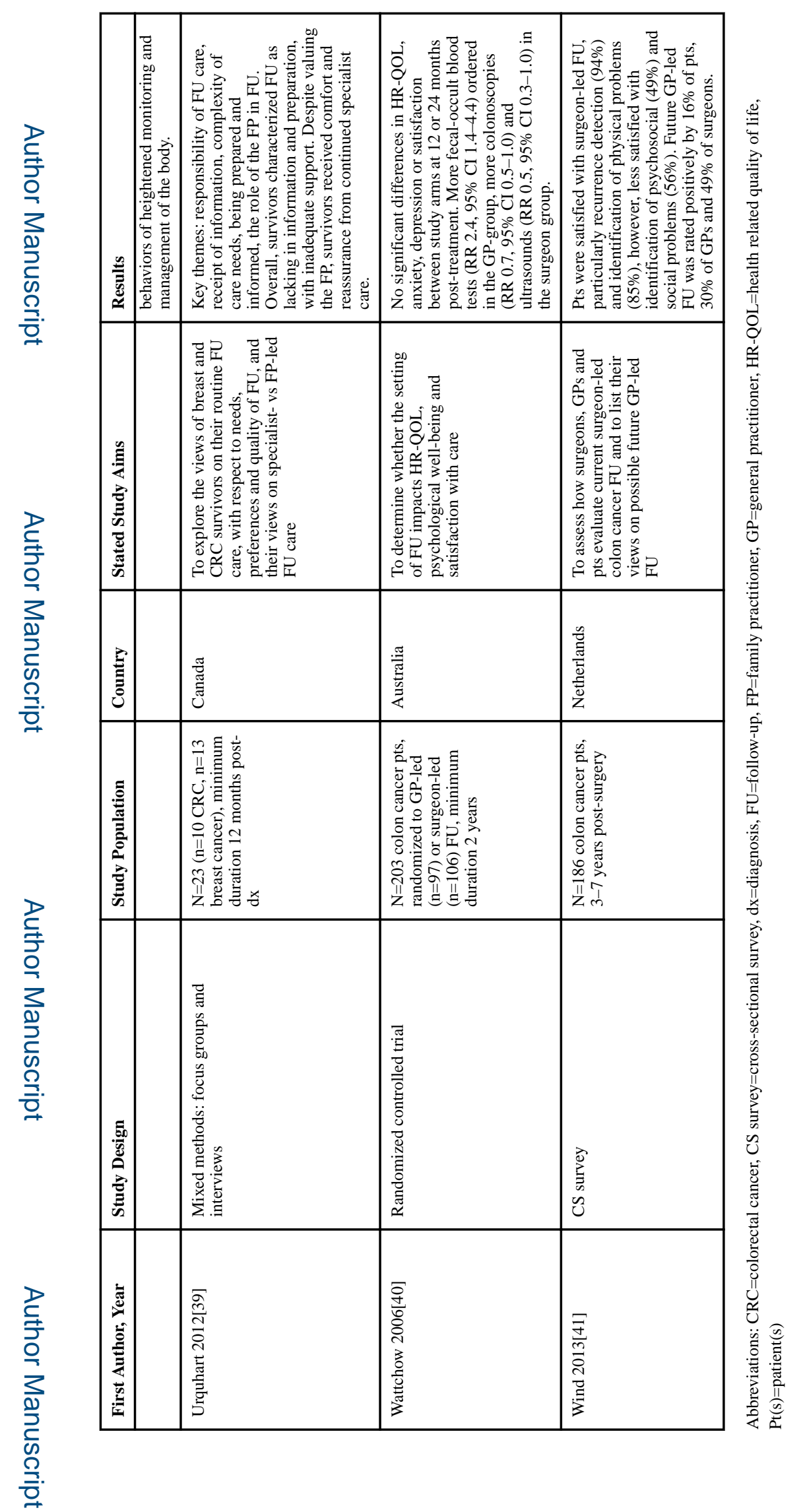

J Cancer Surviv. Author manuscript; available in PMC 2018 October 01. 


\section{TABLE 2}

\section{Perceptions of Follow-Up Care}

\begin{tabular}{|c|c|c|}
\hline Theme & Positive perceptions & Negative perceptions \\
\hline $\begin{array}{l}\text { Emotional reactions to follow-up (E.g., positive = } \\
\text { reassurance, negative = anxiety) }\end{array}$ & $\begin{array}{l}\text { N=7 (Cardella 2008; Kjeldson 1999; } \\
\text { Papagoriadis 2003; Rosmovitz 2004; } \\
\text { Steele 2007; Stigglebout 1997; Sterba } \\
\text { 2015) }\end{array}$ & $\begin{array}{l}\mathrm{N}=2 \text { (LiDestri 2000; Taylor } \\
\text { 2011) }\end{array}$ \\
\hline Overall satisfaction or perceived quality of care & $\begin{array}{l}\text { N=4 (Arora 2011; Papagrigoriadis 2003; } \\
\text { Pisu 2014; Stigglebout 1997) }\end{array}$ & $\mathrm{N}=1$ (Miedema 2003) \\
\hline Access to care or frequency of visits & $\begin{array}{l}\mathrm{N}=4 \text { (Arora 2011; Beaver 2011; Cardella } \\
\text { 2008; Stigglebout 1997) }\end{array}$ & $\mathrm{N}=0$ \\
\hline Follow-up is important to detect recurrence & $\begin{array}{l}\text { N=3 (Cardella 2008; DiFabio 2008; Pisu } \\
\text { 2014) }\end{array}$ & $\mathrm{N}=0$ \\
\hline Follow-up is important to improve survival & $\mathrm{N}=2$ (Cardella 2008; Kjeldson 1999) & $\mathrm{N}=0$ \\
\hline $\begin{array}{l}\text { Information exchanged during follow-up (e.g., ability to ask } \\
\text { questions, questions answered) }\end{array}$ & $\begin{array}{l}\text { N=3 (Beaver 2011; Pisu 2014; Urquhart } \\
\text { 2012) }\end{array}$ & $\begin{array}{l}\mathrm{N}=2 \text { (Arora 2011; Miedema } \\
2003 \text { ) }\end{array}$ \\
\hline Communication between providers & $\mathrm{N}=0$ & $\begin{array}{l}\text { N=2 (Beaver 2011; Miedema } \\
\text { 2003) }\end{array}$ \\
\hline $\begin{array}{l}\text { Follow-up includes sufficient sensitivity to patients' quality } \\
\text { of life }\end{array}$ & $\mathrm{N}=0$ & $\begin{array}{l}\text { N=3 (Arora 2011; Beaver 2011; } \\
\text { DiFabio 2008) }\end{array}$ \\
\hline
\end{tabular}

$\mathrm{N}=\#$ Articles with emphasis on positive / negative perceptions according to the stated theme (row). 